第20回情報知識学フォーラム予稿

\title{
Linked Dataにこよる分野連携型データベースの枠組み
}

\section{The framework for cross-disciplinary databases with Linked Data}

\author{
武田英明 ${ }^{1 *}$, 加藤文彦 ${ }^{2}$, 大向一輝 ${ }^{3}$ \\ Hideaki TAKEDA ${ }^{1 *}$, Fumihiro KATO ${ }^{2}$, Ikki OHMUKAI ${ }^{3}$
}

1 国立情報学研究所, 総合研究大学院大学

National Institute of Informatics

厂101-8430 東京都千代田区一ツ橋2-1-2

E-mail: takeda@nii.ac.jp

2 情報・システム研究機構, 国立情報学研究所

Research Organization of Information and Systems

干 105-0001 東京都港区虎ノ門4-3-13 ヒューリック神谷町ビル2階

E-mail: fumi@nii.ac.jp

3 国立情報学研究所, 総合研究大学院大学

National Institute of Informatics

テ101-8430 東京都千代田区一ツ橋2-1-2

E-mail: i2k@nii.ac.jp

本稿ではLinked Dataの仕組みがいかに分野を横断して連携するデータベースを構築することを 可能としているかを述べる。 Linked DataはセマンテイックWebの技術を使い、Web of Data、すなわち Dataが相互につながったような世界をつくることを可能とする。実際、世界においてはDBpediaを中 心として500以上のデータセットが相互につながっている。国内においては著者らが2012年より

DBpedia Japaneseを公開・運営することで、同様の活動を広めている。実際、2012年以降、50以上の 研究報告があり、20件のデータセットがリンクされており、15件のアプリケーションが報告されている。 またその内容も生物学から文化的コンテンツまで幅広く、様々なデータベースがリンクできることがわ かる。

In this article, we discuss how Linked Data is suitable to create cross-disciplinary database with respect to the mechanism and the existing datasets. Linked Data mechanism is to provide "web of data" by describing data with RDF while the traditional Web pages consist of "web of documents" with HTML. In particular, DBpedia, LOD of Wikipedia, has accelerated creation of other LODs since 
DBpedia works as a hub to link cross-disciplinary datasets. We have launched DBpedia Japanese with expecting the same effect in Japan. Indeed, we observed many new activities to expend Linked Data cloud in Japan, more than 50 technical reports, 20 directly linked datasets and 15 applications.

キーワード: Linked Data, Linked Open Data (LOD), DBpedia, DBpedia Japanese, 分野横断型データベース Keyword: Linked Data, Linked Open Data (LOD), DBpedia, DBpedia Japanese, cross-disciplinary database

\section{1 はじめに}

Linked Open Data(LOD) とはWeb技術、こ とにセマンティックWebの技術を用いたデ ータの公開・共有の技術を持いたデータベ ースのことである。World Wide Web（以下 Web)がその技術によって、世界中の文書が インターネットを介して繋がった世界

(Web of Documents) を作ったのに対して、 LODはデータの繋がった世界(Web of Data) を作ることを可能としている。Webの画期 的な点は、これまで本や個別の文書に閉じ ていた情報同士の関係をオープンかつフ ラットに結びつける仕組みを提供したこ とであり、このことによりこれまでの社会 にあった様々な部門や組織、分野にあった 様々な情報が一様に結びつくようになっ た。LODも同様にこれまでの部門や組織、 分野などを超えてデータが結びつくこと を可能としている。

本稿では、まずLODの概要を述べた上で、 LODが実際に使われている状況についての 報告を行う。ことに日本においてはこの2 年ぐらいでLODが急速に利用されるように なっている。その点について調査結果を報 告する。

\section{Linked Open Data (LOD)とは}

セマンティック Web とは Tim

Berners-Lee 氏が提唱した現行の Webよ り高度に知識を記述できる Web をつくる というビジョンである。そのポイントは
Web のグローバルな情報共有空間はその ままに、その上に標準的なメタデータの記 法である RDF やそのスキーマを記述する 言語（RDF Schema や OWL）を用意する ことで、グローバルに知識を共有する仕組 みである。Linked Open Data (LOD)は基 本的にこのセマンティック Web の技術を 使っている。ただし、記述する対象が文章 からなる文書的情報(HTML 文書)ではなく、 データであることだけが違いである。

LOD を構成する仕組みが簡単である。まず、 RDF(Resource Description Framework) という言語で全てを書く。RDF はとても簡 単な言語で、「主語」「述語」「目的語」に相 当する 3 つ組で全ての情報を書く言語であ る。例えば「Aさんは B さんを知っている」 という関係は「A knows B」という3つ組 で表現される。このとき表現したい事物 (例 えば、前述の例では A、B）には個別の URI を与える。URI は URL を一般化したもの で URL も含んでいるものであるが、URL は Web ページの場所を示す (その URL を 見にいけば Web ページがある)のに対して、 URI は必ずしも Web ページがなくてもよ い。ここでは個々の事物に URI を振ること で、URI が世界中でユニークな ID として 使えることが重要である。また事物だけで なく関係も URI で表現することができる。 そうすることで、ある 3 つ組の中で使って いる関係（例えば knows）が別の 3 つ組の 中で使っている関係と同一であるというこ 
とを示すことができる。

原理は基本的にこれだけである。この RDF で表現された 3 つ組の情報を組み合わせて いくことで、複雑なデータも記述すること ができるし、さらには異なるデータセット の中にあるデータ間の関係も書くことがで きる。

\section{LODが作る世界}

URI と RDF を使うことでデータはデータ がどこに含まれているといったことを気に せずに相互につなげることができる。これ は新しいデータの世界である。Tim Berners-Lee はこの LOD を普及させるた めに 4 つの原則を提唱している。

1. 事物をURI を使って名前付けしょう

2. 名前の参照が HTTP URI でできるよ うにしよう

3．URI を参照したときに関連情報が手に 入るようにしよう

4. 外部へのリンクも含めよう

この原則に基づくとデータセットは相互に つながり、データセットのネットワークが できる。これをLOD Cloud と呼んでいる

(図 1 参照) 1。図 1 において、丸が個別 のデータセットを示し、データセットとデ ータセットを結んでいる線は、データセッ ト内のデータ同士にリンクがあることを示 している。

この図ではデータセットを 9 種類に分けて いる。政府関係(Government)、出版関係 (Publications)、ライフサイエンス (Life sciences)、ユーザ生成コンテンツ

1 "Linking Open Data cloud diagram 2014, by Max Schmachtenberg, Christian Bizer, Anja Jentzsch and Richard Cyganiak. http://lod-cloud.net/"
(User-generated content)、分野横断 (Cross-domain)、メディア(Media)、地理 関係(Geographic)、ソーシャル Web(Social web)である。

中心にあるのは DBpedia で、Wikipedia の情報をLOD化したデータセットである。 Wikipedia は百科事典なので、様々な分野 の項目が含まれている。このため、他の多 くのデータセットと結びつきやすい。この ため、DBpedia はこの図の中心にある。 なおこの図にあるは Data Hub と呼ばれる データカタログに登録されたデータセット のうち、以下の基準を満たしたものである [Cyganiak 11]。

1. 解決可能な http://(または https:/l) URIs でなければならない。

2. content-negotiation 等でよく使われ る $\mathrm{RDF}$ 形式 (RDFa, RDF/XML, Turtle, N-Triples）のいずれかで RDF データを解決できなければならない。

3. 1000 トリプル以上含んでいる。

4. 他の既存データセットとの RDF リン クが 50 以上ある。

5. RDF クローリングまたは RDF ダン プ，あるいは SPARQL エンドポイン トによってデータセット全体にアクセ スできる。

加えて

6. 認証なしかつ無料でアクセスできる。 も事実上の基準である。この図において 500 個以上のデータセットが相互にリンク し合っている。

\section{DBpedia Japaneseの運用}

先に述べたようにDBpediaは様々なデータ セットからリンクされるLODのハブとして 機能している。このようなハブがあることが 


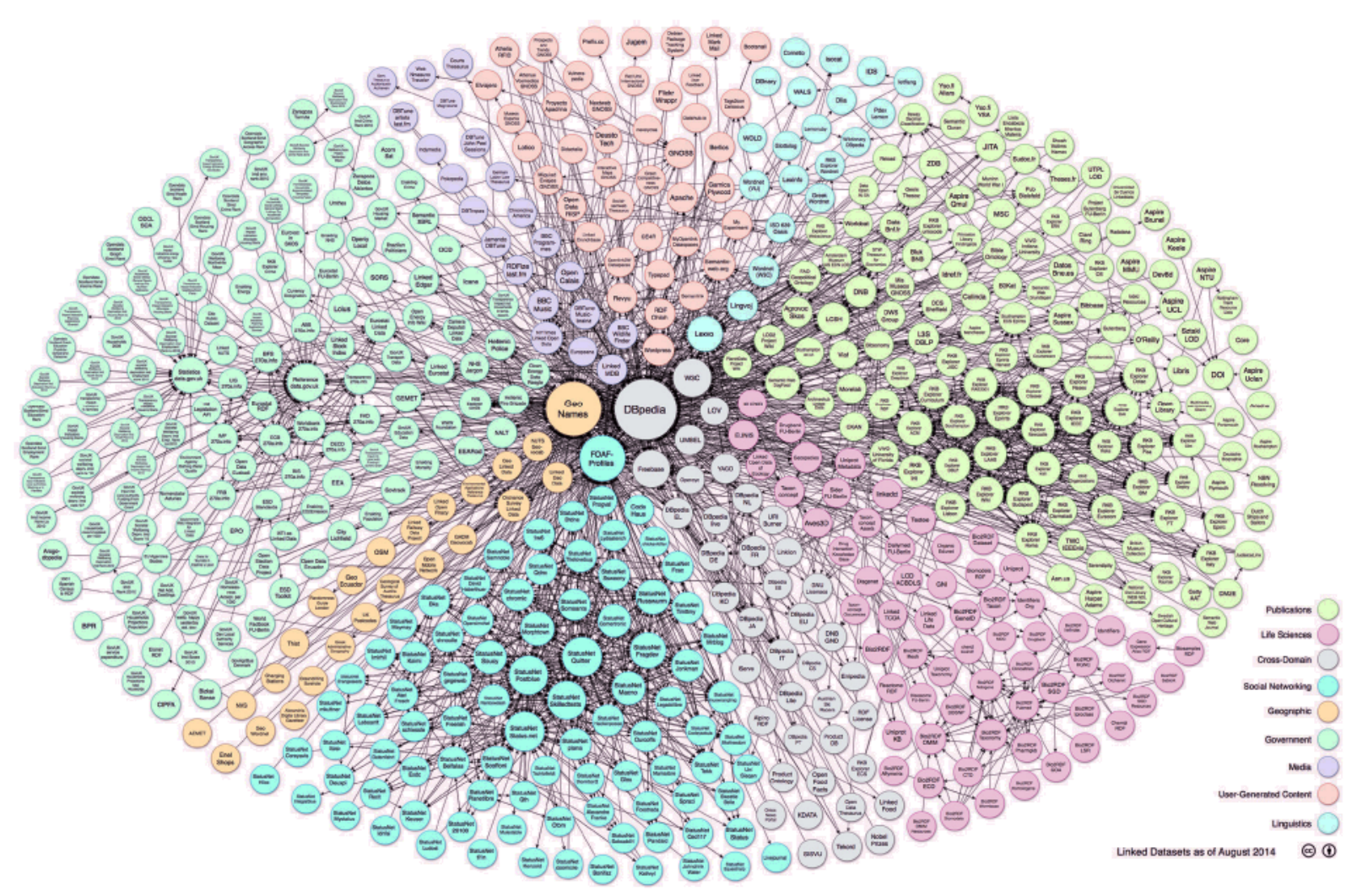

図 1 : LOD Cloud

LODの相互参照を促す仕組みとして有効で ある。このため、我々はDBpedia Japanese の運用を行なっている。

DBpediaは英語版Wikipediaから作られてい る。このため英語版Wikipediaにある項目は 存在し、その情報もLODとして提供されてい る。さらにWikipediaの言語間リンクの情報 を利用して、もし項目に各国語版がある場合、 DBpediaはその各国語版での表記をその言 語のラベルとしてRDFとして記述している。 このためある程度日本語で表記された項目 を対応づけることはできる。しかし、日本版 Wikipedia独自の項目は当然存在しないし、 また各項目の属性や属性值も英語版と日本 語版では異なるにもかかわらず、英語版から 取得した属性・属性值しか用意されていない。 このため、我々は日本語Wikipediaから構築 するDBpedia Japaneseを運用することにし た。
DBpedia構築に当たってはDBpedia

Information Extraction Framework ${ }^{2}$ と呼ば れる一連のソフトウエアを使うことで、

Wikipediaからほぼ自動的に構築することが できる。これは言語の異なるWikipediaに適 用可能である。

ただし、いくつかのことはDBpediaを有用に するために言語ごとに行う必要があった。

・ i18n(国際化)に関わるコード改善

- Wikpedia内の表記に依存した処理の対 象言語への置き換え（例：日付の処理）

- オントロジーの対応（新しい概念の追加 と既存の概念とinfoboxやその属性への 対応付け)

2012年から運用を始めている。Wikipediaの ほうは日々更新されているものの、DBpedia

2

https://github.com/dbpedia/extraction-fra mework 
Japaneseは現在は自動更新ではなく、適宜更 新されている。

\section{DBpedia Japaneseの利用}

先に述べたようにDBpediaは様々なデータ を結びつけるハブとして期待されている。 2012年から論文等でDBpedia Japaneseが利 用されている件数を図 2 に示す 3 。現在のとこ ろ、全体で58件であった。 データセットに関しては20件であった（図3 参照)。出版・文化関係、生物学・ライフサ イエンス、政府関係が数的に多く、これは本 家のLOD Cloud掲載のデータセットの傾向 と似ている。

利用しているアプリケーションとしては 15 件を発見している（表2)。アプリケーション は汎用ツール（検索・可視化など）と特定分 野の検索に大別される。とくに特定分野の検 索においては音楽、スポーツから歴史まで 様々な分野に適用されていることがわかる。 これはDBpediaの汎用性が活かされている といえる。

\section{6 日本におけるLOD}

図 1 に示した LOD Cloud には国内で作ら れ、公開された LOD はほとんど含まれて いない。国立国会図書館が公開する 典拠と件名標目（Web NDL Authorities）と DBpedia Japanese のみが掲載されている。 これは本家 LOD Cloud は事実上オープンデ ータが求められていたり、一定数の外部リン クが必要などがあるため、国内のデータセッ トがなかなか基準を満たせないことがある。

3 DBpedia Japaneseが利用されているかど うかを知るの容易でなく、関連する学会、国 際会議や検索などを用いて調査した。このた め、必ずしも網羅しているといえない。

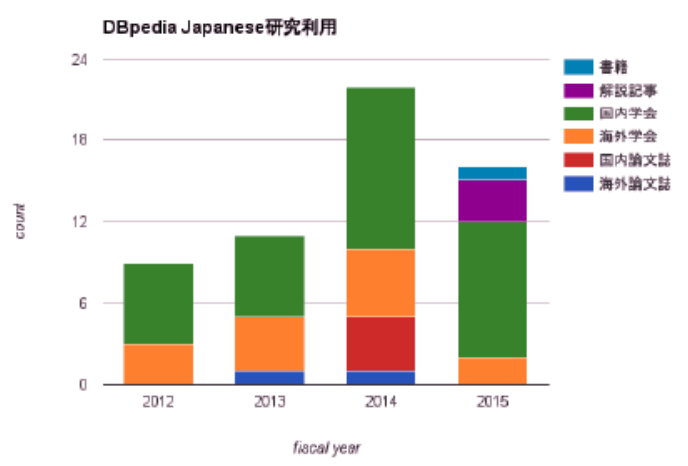

図 2:DBpedia Japanese の研究利用推移

そこで、我々はやや基準を緩めてリンクする 国内のデータセットを調査した $[2]$ 。

・ データ公開者が日本にいる人・組織等で ある

・日本語ラベルを含んでいる

・ 1000 トリプル以上含んでいる

・ 本家図か JLDC 図の既存のデータセット との RDF リンクが 10 以上ある

・ 参照解決可能な状態, データダンプ, あ るいは SPARQL エンドポイントのいずれ かによってデータセットを公開してい る

この基準に従ったデータセットのネットワ ークを図 4 に示す。

\section{LOD 化に関する考察}

\section{1 繋がるデータのメリット}


表 1 : DBpedia Japanese にリンクしているデータセット

\begin{tabular}{|c|c|c|}
\hline F゙ータ十卟茗称 & 分野 & URIL \\
\hline J-GLOBAL knowledge & 出版、文化(Fublication) & httos:/stinff globel st. 90 is/ \\
\hline LODAC Museum & 丮版, 文化(Fublication) & htto/flodac \\
\hline 日本語Wikipedia才 才トロシー & 涯用 (Cross-dorain) & htto:/4mww.sikiresieontologyorg \\
\hline LODAC Species & 生肳学、ライフサイエンス (Life Solence) & htto:/hadac/species/ \\
\hline 京都国際マソガミューソアム書註”静部 LOD & 出版，文化(Fublisation) & htto//mclabs sis tsulhute ac.p/lode2012/kmm/ \\
\hline GeoLOD & ttete理(Ceographic) & htto//geoladex.rii.ecio/ \\
\hline ライフサイエン人辞青 & 生物学、ライフサイエンス (Life Soience) & htto://sodeds ip \\
\hline WordNet-ja & 师用(Cross-donain) & htto://wordnetio \\
\hline Open DATA METI LOD & 欧府(Govemment) & htto//datamet go. $\mathrm{p}$ \\
\hline 東日本大震赑アーカイプFukushima & 政府 (Government) & htto.//fukushime archive disesters jo \\
\hline 曝三LLOD & 政府(Government) & 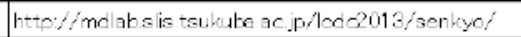 \\
\hline ヨコルマ・アート・LOD & 出版、文化(Fublicatior) & htto:/fp yaf o.org/yokohama art logl \\
\hline 青空交亚 Linked Open Data & 出版。文化(Fublication) & htto//ndlabs is tellate ac.p/lod $2012 /$ aozoralod \\
\hline NHK晎象マップロらしくLOD & 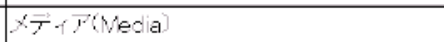 & htto://molab.s is tsukute ac. p/lode201\%/michishiru \\
\hline faLLOD & 库業(Indutry) & httoffmonodzukurilodorg/nojif \\
\hline LSJ: Location Site of Japanimation & t地理 (Geographio) & htto://chesse foctory.info/ \\
\hline 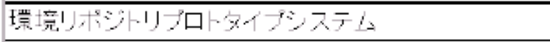 & 生物学、ライフサイエンス(Lif日 Soience) & httoffrihnexers chikyuacjo \\
\hline Georames.jo & t地理 (Geographio) & htto://g=onemes.jp \\
\hline 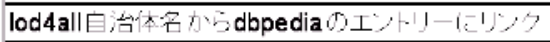 & 批理(Geographic) & htto/Aod4all.net/lode/city-comp \\
\hline Evacva & 政府(Government) & htto://eva cvenet \\
\hline
\end{tabular}

表 2 : DBpedia Japanese を利用したアプリケーション

\begin{tabular}{|c|c|c|}
\hline 宝前 & 分頻 & URL \\
\hline ここベティア & 地区ナビゲーション & 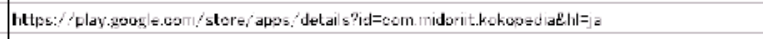 \\
\hline ア゚ロ野球因箱ナーチ & 特定分野抬䒺(スボーツ) & hetpif/inner-search.com \\
\hline MLLSICSPARQL & 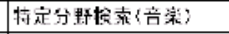 & htp: /m maicspard.appsotocom \\
\hline SPARQL Timelingr & 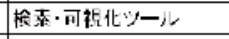 & 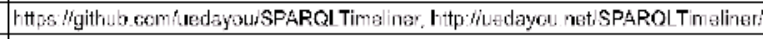 \\
\hline 几次の院た!! & 惨素·可視化ツー心 & hetp://nzinonedatzriaz ure wobsit.os.net \\
\hline 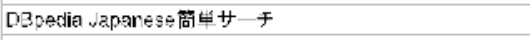 & 捡东·可䄈化ツ一心 & htto:/locosaka.hozo.jpiEasyoD/index chpecia_a.html \\
\hline 冓フ筑りマ・ンター & 梌䒺·可祝化ツ一心 & 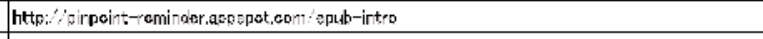 \\
\hline DashSearch LD & 搈素·可镇化ツール & 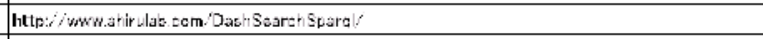 \\
\hline 总虫コンパス & 特定分野控素使击： & 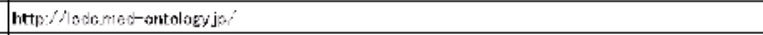 \\
\hline ハイオシメティクス・オントロジーによるキーーワート゚妳察システム & 特定分斯信索（生物） & http:/'tiominatics.horo.jp' \\
\hline 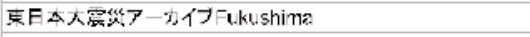 & 特定分野データバース & 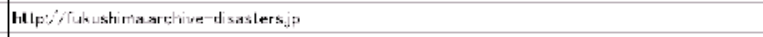 \\
\hline ウィギ町中ビュフー & 特定分野隐索(肯史) & hitlp://ce-study appsoot com/m, torm tim=lins \\
\hline
\end{tabular}

1 章で述べたように LOD を使うことで慗 がるデータを公開できる。データベース公 開側にとって二つの意味がある。一つは、 外部へのリンクを含むことで、自分のデー タベース利用者の便益を上げるということ である。例えばある美術作品のメタデータ を公開している時、その作者を文字列だけ で示すのではなく、DBpedia の該当項目へ リンクをつけることで、データベース利用 者はより便利に使うことができる。に番目 の意味は、他のデータベースから自分のデ ータヘリンクを貼ってもらうことによる、 データベースの利用の促進である。自分の データベースにある美術作品が他で言及さ れている時に、この項目にリンクをつけて
もらえれば、これまで自分のデータベース の利用者でない人も結果的に利用すること になる。

\subsection{LOD に向くデータベース}

どんなデータベースでも原理的に LOD 化 することは可能であるが、ときに LOD 化 のメリットが大きいデータベースは以下の ようなものである。これは前章のメリット に対応するものである。

1. 自身がハブ的データになっているも の：すなわち、他から参照される利用 の仕方が多いものは、LOD 化のメリッ トは大きい。DBpedia もそうであるし、 辞書なもの、あるいは分野ごとの基礎 的なデータベース（例えば医薬品のデ 
ータベース、生物種のデータベース、 人名データベース）などが含まれる。

2. 外部参照を含むことで自分のデータの 価值が上がるもの：美術品データベー ス、書誌などは典拠や人名などのデー タベースにリンクすると自身の利用価 值が上がる。

3. そもそも構造がネットワーク的なデー タベース:外部参照、被参照がなくて、 例えば SNS のデータなど、自分自身が ネットワーク構造のデータあるものは LOD 化したほうが利用しやすいデー タベースになる。

\subsection{LOD を念頭においたときのデータ}

\section{ベース設計}

このような外部参照、被参照を前提とした とき、データベースの設計も自ずと変わっ てくる。

1. データのエンティティの単位を明確に する。一つの事象、事物に対応するよ うなエンティティを用意して、それに 明確な方法で（できれば識別子に基づ いて）URI を与える。そのエンティテ イにその事象、事物に直接関係しない ようなことは含めないようにする。

2. データ構造を複雑にしない。データ構 造が複雑になる場合、往々にして本来 分離すべき別の事象・事物をまとめて 構造にしていることがある。そういう 事物・事象は別のエンティティとして 管理し、リンクで関係付ける。

3. データ構造は汎用のスキーマを参照し て設計する $4_{\circ}$ そのまま使えなくても対

4 例えば、Linked Open Vocabulary (LOV, http://lov.okfn.org/dataset/lov/)には世界 の LOD で使われているスキーマが登録さ れている。また経済産業省/IPA が開発して

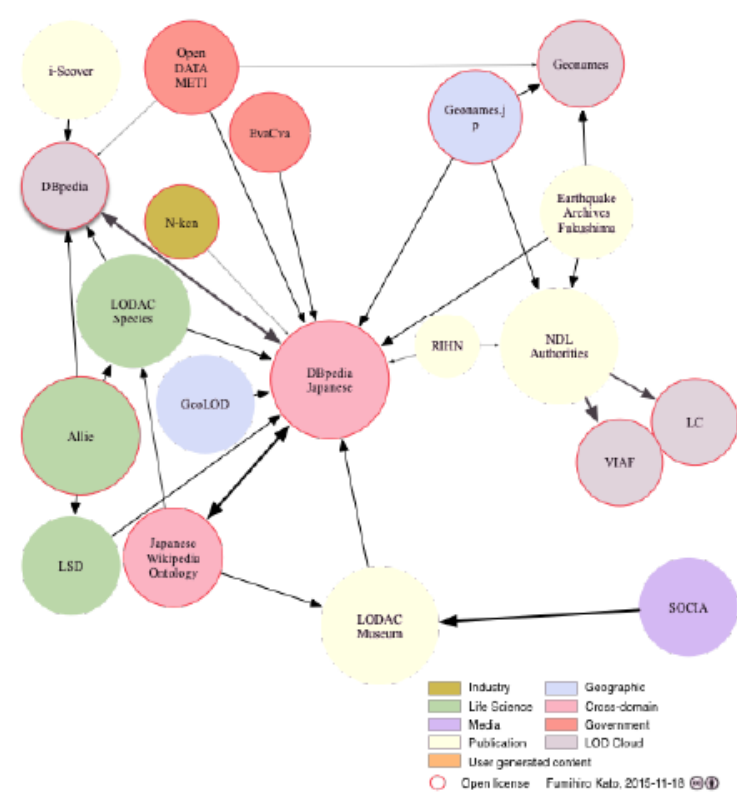

図 3 : Japanese Linked Data Cloud (JLDC)

応関係を書くなど、汎用スキーマとの 関係を記述することが望ましい。

4. 個々のデータベースはその主題に関す るデータ提供に徹する。もし、データ ベースの主題ではないが、ユーザにと って有用な情報があり、それが他のデ 一タベースによって提供される情報で あるならば、他のデータベースへのリ ンクによって補うようにする。

これは LOD として利用価值の高いデータ ベース設計の方法論であるが、またこれは 管理しやすく、長期にわたって維持更新の しやすいデータベースの設計方法論でもあ る。

8. まとめ

本稿ではLinked Dataがいかに分野横断的デ 一タベースを作りうるかついて、実例を交え ながら説明を行った。データがリンクするこ

いる標準語彙基盤

(http://goikiban.ipa.go.jp/)もある。 
とで、様々な分野が繋がるというのは、単に 便利になる以上の価値がある。思いがけない 分野の組み合わせが生まれ、新しい研究が生 まれる可能性がある。このためもまずはよく 整備されたデータベースを持っている研究 者・機関はそれをLinked Data化することで、 このweb of dataの世界を広げる先陣となる ことが望まれる。

\section{参考文献}

[Cyganiak 11] Cyganiak, R, Jentzsch, A: The Linking Open Data cloud diagram, http://lod-cloud. net (2011)

[2] 加藤文彦, 武田英明, 小出誠二, 大向 一輝：日本語Linked Data Cloud の現状, 人工知能学会全国大会 (第28回), No. 1G5-0S-19b-7, 松山市 (2014). 